DIW BERLIN

Discussion

Papers
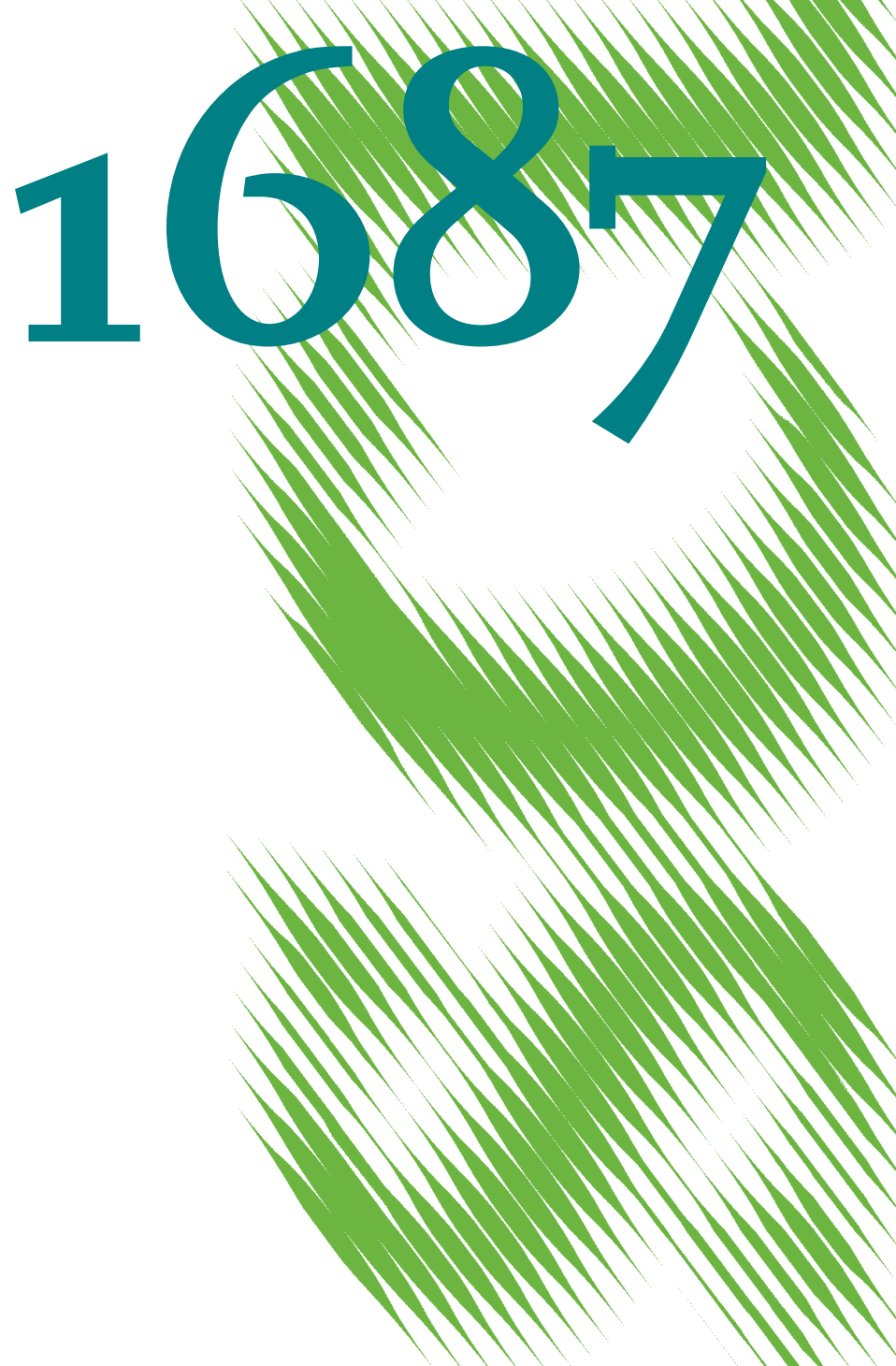

Does Quality of Early Childhood Education and Care Affect the Home Learning Environment of Children? 
Opinions expressed in this paper are those of the author(s) and do not necessarily reflect views of the institute.

IMPRESSUM

(C) DIW Berlin, 2017

DIW Berlin

German Institute for Economic Research

Mohrenstr. 58

10117 Berlin

Tel. +49 (30) $89789-0$

Fax +49 (30) $89789-200$

http://www.diw.de

ISSN electronic edition 1619-4535

Papers can be downloaded free of charge from the DIW Berlin website:

http://www.diw.de/discussionpapers

Discussion Papers of DIW Berlin are indexed in RePEc and SSRN:

http://ideas.repec.org/s/diw/diwwpp.html

http://www.ssrn.com/link/DIW-Berlin-German-Inst-Econ-Res.html 


\title{
Does quality of early childhood education and care affect the home learning environment of children?
}

\author{
Susanne Kuger (DIPF Frankfurt) \\ Jan Marcus (Universität Hamburg and DIW Berlin) \\ C. Katharina Spiess ${ }^{1}$ (DIW Berlin and Freie Universität Berlin)
}

\section{September 2017}

\begin{abstract}
Both, a high quality of the Early Childhood Education and Care (ECEC) setting and a high quality of the home learning environment foster children's development. However, we know little about the interactions between ECEC quality and the home learning environment. We examine whether the child's attendance in a high ECEC quality setting improves the quality of her home learning environment. We use very rich data from the NICHD Study of Early Child Care and Youth Development (SECCYD), which provides detailed panel information through children`s age of 6 months to 9 years on ECEC quality and on the child's home learning environment. Our analysis is based on a sample of 700 children who have been in non-family child care for at least 10 hours/week. We estimate level and value-added specifications and show that ECEC quality improves the home learning environment at various measurement points. The effects sizes indicate that an increase in ECEC quality by one standard deviation increases the home learning environment by about 0.08 standard deviations. Furthermore, results differ by sub-groups: The home learning environment from more advantaged children benefits more from higher ECEC quality. Thus the potential of high ECEC quality on the home learning environment is not effectively used for disadvantaged children. Policies could work on this potential link, in particular.
\end{abstract}

JEL: J13, I20, I24

Keywords: ECEC quality, home learning environment, spill-over, disadvantaged children

\footnotetext{
${ }^{1}$ Corresponding author: C. Katharina Spiess, DIW Berlin, Mohrenstrasse 58, 10117 Berlin, Germany, kspiess@diw.de.
} 
There is a large body of international research in economics and other social sciences on the effects of Early Childhood Education and Care (ECEC) on the cognitive and non-cognitive (socio-emotional) development of children. While many of these studies focus on quantitative aspects (i.e., whether and how long a child attends ECEC settings), several psychological and pedagogical studies emphasize that attendance, per se, is less predictive for child development than ECEC quality. This growing literature shows that attending ECEC services of higher quality is positively associated with children's development, with effects increasing with ECEC quality (e.g., Belsky et al. 2007, Sammons et al. 2008, Vandell et al. 2010; for an overview see Melhuish er al. 2015). ECEC quality is also crucial for the magnitude and the long term persistence of beneficial effects (for international and US reviews see, e.g., Gilliam and Zigler 2001, Gorey 2001, Anderson et al. 2003, Burger 2010, Camilli et al. 2010). In the economic literature, mainly intervention studies demonstrate the beneficial effects of high quality ECEC (famous interventions include the Perry preschool program or the Abecedarian program, e.g., Heckman et al. 2013, Kautz et al. 2014), where children attend high ECEC quality programs as part of the intervention. ${ }^{2}$

In addition to the literature on the effects of ECEC quality, another strand shows that the home learning environment (HLE), and parental investments are important for children's cognitive and non-cogntive development. Apart from studies in other disciplines, here the economic literature covers more studies (see below). In these studies parental investments are often measured by financial inputs or time inputs. Few studies focus on the activities parents undertake with their children. The literature stresses the importance of parenting compared to parental income (for a recent study on this see Carneiro and Ginja 2016). ${ }^{3}$ Several studies give empirical evidence that mother's time is a crucial investment in the production process of child outcomes. Father's time is almost equally productive, especially during crucial stages of development (e.g., Carneiro and Rodriguez 2009, Del Boca et al 2014, Del Bono et al. 2016). However, the effects depend on the activities parents perform with their children: Hsin and Felfe (2014), for instance, show that the time mothers spend on educational and structured

\footnotetext{
${ }^{2}$ There are very few studies by economists that explicity analyse the effects of the quality of average ECEC programs, which are open to all children: For instance, Araujo et al. (2016) study ECEC centers in Ecuador, while Bauchmüller et al. (2014) and Jensen et al. (2015) use samples of Danish ECEC centers.

${ }^{3}$ High-quality parenting can be available to a child even when the family experiences adverse financial circumstances, although higher income facilitates good parenting. In part, this observation accounts for the success of children from certain cultural and ethnic groups raised in poverty who nonetheless receive strong encouragement from devoted parents and succeed (Cunha and Heckman 2009).
} 
activities correlates positively with child outcomes, more than the time spend on other activities.

Todd and Wolpin (2007) use a home environment index as a measure for parenting, and find strong evidence that home inputs are important determinants of child cognitive development. Using the same scale, Blomeyer et al. (2013) also demonstrate that the home learning environment is strongly related to competencies during childhood and achievement in adulthood. The importance of high quality parenting for child development is further underlined by evaluations of few interventions that try to improve maternal skills to develop children's skills. This small literature suggests that these programs are particularly effective when addressing disadvantaged mothers. ${ }^{4}$

Overall, benefits of high ECEC quality and home quality on child development are wellestablished. Yet, we know little about the interrelations of these two important types of investments. In particular, there is almost no evidence on the effect of high ECEC quality on the quality of the home environment. However, it is crucial to understand how parents react to better ECEC quality. Do they substitute higher ECEC quality with lower HLE quality, do they complement higher ECEC quality with higher HLE quality, or is the provided level of HLE quality completely unrelated to the ECEC quality? The answer to this question is relevant for researchers and policy makers. If an increase in ECEC quality results in a lower HLE quality, investments in higher ECEC quality are not necessarily beneficial. The effect of higher ECEC quality is only unambiguously positive, if ECEC quality either leaves HLE quality unaffected or increases it.

There is some evidence that children require a minimum level of support from the home environment to benefit from higher ECEC (e.g., NICHD 2002, Vandell et al. 2010), while others argue that disadvantaged children especially benefit from high ECEC quality as it compensates for low HLEs (for an overview, see, e.g., Elango et al. 2015). A few studies describe the correlations between ECEC quality and the quality of the HLE in the social science literature (e.g., NICHD 1997, McCartney et al. 2007, Habibov 2012, Lehrl et al.

\footnotetext{
${ }^{4}$ The Nurse Family Partnership Act, which intervenes solely with pregnant teenage mothers and teaches them mothering and infant care, has substantial effects on the adult success of the children of disadvantaged mothers (Cunha and Heckman 2009). Olds (2002) documents that perinatal interventions to reduce mother's potential risky behavior have substantial long-term effects on cognition, socioemotional skills, and health, and have high economic returns.
} 
2014). ${ }^{5}$ For instance, it is shown that higher ECEC quality is associated with improvements in the quality of the home environment, most notably for poorer families. ${ }^{6}$ In the economic literature, this relationship is only studied by looking at very specific high quality interventions for disadvantaged families. Heckman and Mosso (2014) summarize evidence from the Nurse-Family Partnership (NFP, Olds et al. 2007), the Perry preschool program (Schweinhardt et al. 1993) and the Abecedarian programm (Breitmayer and Ramey 1986). The NFP program provided home visits where teenage mothers were provided parenting training. The Perry program offered home visits in addition to preschool attendance and the Abecedarian program interacted with parents of the treatment group at the day care centers. The evidence generally supports complementary responses of parents to such interventions ${ }^{7}$. This evidence is only based on specific, high intensity, small-scale intervention studies that included a parental training component, sometimes next to child interventions. Our study is the first to analyze the effects of ECEC quality on the overall HLE of children in average ECEC programs that, on average, do not include an explicit parent component. ${ }^{8}$

Our analysis is based on very rich data of the NICHD Study of Early Child Care and Youth Development (SECCYD). This US dataset is the most suitable data set for our research questions as it provides comprehensive information about the child's HLE before and after being in ECEC and that it covers detailed ECEC quality measures, which go far beyond simple structural characteristics (e.g., staff-child ratio or group size) as they are based on observations of professionally raters. We estimate value-added models and exploit the rich SECCYD data by including a wide range of additional variables controlling for other past and current inputs, including some variables (like non-cognitive skills) that are often unobserved to the researchers. We show that ECEC quality has a positive effect on the HLE of children. This effect is more pronounced for ECEC quality experienced at ages two or later. Our results

\footnotetext{
${ }^{5}$ There are a few descriptive studies on the relationship between non-parental care use and parental time in activities with children. For instance, Bittman et al. (2004) examine the relationship between non-parental care and the amount and quality of parental engagement using Australian data, while Booth et al. (2002) use the same data as we do to study the use of childcare for 300 hours and more and the mother-infant interaction. However, these studies do not consider ECEC quality, they only focus on the dose of care.

${ }^{6}$ However, this result by Mc Cartney et al. (2007) is not further elaborated and only one intermediate step toward the answer to the question of different pathways to explain the effect of ECEC quality on child development.

${ }^{7}$ Heckman and Mosso (2014) report intervention effects on a set of various measures of parenting quality, by children's gender and program duration.

${ }^{8}$ A study by Araujo et al. (2016) investigates the effect of universal kindergarten teachers' quality on child outcomes in the US. Their analysis on the mechanisms shows that kindergarten teachers' quality not only does not change parental investments and behavior toward children, but also that parents can distinguish between high and low quality teachers. However, the study only focuses on teacher quality and not on overall ECEC quality.
} 
are robust to various model specifications, taking into account measurement and sample restriction issues. However, there are substantial differences between various groups: The effects mainly occur for more advantaged children, white children, those of higher educated mothers, and those of non-single mothers. These results suggest an additional mechanism exerting the previously discussed "Matthew Effect" in ECEC (Vandell et al. 2010). The potential of high ECEC quality to influence the HLE of children is certainly not fully explored and could be extended to more disadvantaged groups.

The structure of this paper is as follows. Section 2 explains the conceptual framework and discusses several mechanisms through which ECEC quality might impact the HLE. Section 3 introduces our empirical approach and the data. Section 4 presents our main results as well as robustness tests and analyses of effect heterogeneity. Section 5 summarizes our findings and concludes.

\section{Conceptual Framework and Mechanisms}

By analyzing the association between ECEC quality and the HLE of a child, we refer to the dynamic skill formation model by Cunha and Heckman (2007). In this framework, the dynamic complementarity of skills results from the fact that investments and skills at time $t$ affect the skill level at $t+1$ and so on. While this technology of skill formation focuses on the multiple distinct developmental periods in childhood and on multiple skills, it also emphasizes multiple forms of investments, including parenting and schooling (e.g., Francesconi and Heckman 2016). In the context of early childhood, schooling can be interpreted as a synonym for all non-parental formal care and education arrangements, covering ECEC services as well. While there is much research on how skills develop according to this model, less attention is paid to the relationship between the different investments. Do they influence each other, either directly or via the skill development of children? How is the relationship between parents, ECEC institutions and children shaped? The fact that this is barely studied is surprising, as in the presence of dynamic complementarities in the production function for skills, the most effective remediation strategy for disadvantaged children, for instance, is to couple increased early investments in various environments with increased investments later. Thus, improving parenting and improving ECEC quality can be complementary investments (this is an extension of the argument by Heckman and Mosso 2014). 
There are several possible mechanisms how the children's HLE and, consequently, home investments are affected by ECEC quality: On the one hand, there might be direct links. As it is a substantial feature of high ECEC quality that the ECEC staff interacts with the parents (e.g., Kluczniok and Roßbach, 2014), educators might directly advise parents on how to improve the HLE - and educators from higher quality ECECs might give better advice. This is also suggested by early childhood educators who report that parents are informally and formally educated in child care settings (e.g., Bowman, 1997): Some child care providers offer informal parent education during drop-off and pickup as well as formal parenting education home visits, workshops, study groups, books, organizational activities, or lectures, for example. If this is effective, it would result in a positive effect of ECEC quality on the quality of the HLE. However, there might be another direct effect, in the sense that parents alter their investments and behaviors to compensate for lower ECEC quality (see, e.g., Todd and Wolpin 2003 or Araujo et al. 2016). Such an effect can only occur if parents are able to judge ECEC quality properly. The small empirical literature on this shows that parents are weakly informed in this respect: Although they overestimate ECEC quality as rated by experts, in general they can distinguish between high and low quality (see, e.g., Mocan 2007 and Araujo et al. 2016). If parents' compensation behavior dominates, we would expect a negative effect of ECEC quality on the HLE quality.

One the other hand, there are several indirect mechanisms. For one, children at home talk about or re-enact their (high quality) ECEC experiences and their parents could learn indirectly from the ECEC educators about ways of dealing with their children as well as about new activities. Second, children benefiting from high ECEC quality might demand more stimulation at home, thus shaping their HLE (e.g., Scarr and McCartney 1983). Third, there might be indirect mechanisms that relate to the parents. A high ECEC quality can also affect parental outcomes, such as parental well-being. There are a few studies focusing on the association between ECEC quality measures and maternal well-being: Higher ECEC quality might reduce work-family conflicts and ensure that children are in good hands (e.g., Kremer 2007, Poms et al. 2009, Payne et al. 2011), consequently increasing parents' well-being. ${ }^{9}$ In turn, increases in parental well-being can improve child development (e.g., Berger and Spieß 2011) and are likely related to improvements in the HLE.

\footnotetext{
${ }^{9}$ Parental, or more precise maternal, well-being can be operationalized as life-satisfaction, stress, or depressive symptoms (e.g., Benasich et al. 1992, Gordon et al. 2011).
} 


\subsection{Empirical approach}

We estimate the effect of ECEC quality on the HLE with a stepwise procedure. In the first step, we regress the HLE measure only on ECEC quality. We then subsequently add further control variables and examine how the estimated coefficient for ECEC quality changes. In the spirit of Todd and Wolpin (2003, 2007), we distinguish between historical and contemporaneous inputs/investments, and we also estimate value-added models (by adding a baseline measure of the outcome variable). In all specifications, we use contemporaneous HLE and past ECEC quality to mitigate concerns about reverse causality.

Our final model is a value-added model with additional controls for past and current inputs:

$$
H L E_{t}=\beta_{0}+\beta_{1} E C E C \text { quality }_{t-1}+\alpha H_{t-1}+\gamma C_{t}+\delta H L E_{t-1}+\varepsilon,
$$

where $H L E_{t}$ is the measure of the current HLE. The parameter of key interest is $\beta_{1}$ and it captures the effect of past ECEC quality on current HLE. $H_{t-1}$ denotes the vector of historical inputs and $C_{t}$ the vector of contemporaneous inputs. $H L E_{t-1}$ is the baseline measure of the HLE. We estimate equation (1) and its variants by ordinary least squares and compute robust standard errors.

\subsection{Data}

Our analyses are based on data from the longitudinal NICHD Study of Early Child Care and Youth Development (SECCYD), formerly the NICHD Study of Early Child Care (SECC). ${ }^{10}$ The study started as a birth cohort study in 1991, recruiting a diverse sample of 1,364 children at different study sites across the US. The consortium applied a range of assessments (questionnaires, ratings, cognitive tests, observations, medical tests) to the sampled children, their families, other non-family care givers, and school representatives. Measurements were initiated when the children were one month old and repeated until 2006, when most children were in grade 9. An advantage of the SECCYD is that panel attrition is rather low, e.g., in grade 3 (the final measurement point in our study, i.e. age 9) the sample still holds 1,076

\footnotetext{
${ }^{10}$ This study was conducted by the NICHD Early Child Care Research Network supported by NICHD through a cooperative agreement that calls for scientific collaboration between the grantees and the NICHD staff. For further information, see https://www.nichd.nih.gov/research/supported/Pages/seccyd.aspx and NICHD (1993, 1994).
} 
children. Most important for the purpose of our study, the SECCYD provides detailed and elaborated measures of quality of the child's ECEC setting (e.g., early child care settings, family care, and nursing) and the HLE - both investments in children.

Outcome. The quality of the HLE is assessed with the Home Observation for Measurement of the Environment (HOME; Caldwell and Bradley, 2003). The HOME is a well-established tool implemented worldwide and used, for instance, by Brooks-Gunn et al. (1996), Aughinbaugh and Gittleman (2003), Todd and Wolpin (2007), Blomeyer et al. (2013), and Carneiro and Ginja (2016). It combines interviewer observations with parental answers to specific interview questions. It is used to assess the cognitive stimulation and emotional support children receive in their home environment. Families' interactions adapt to children's age; thus there are age-specific adaptations of the HOME (age $0-3$, age 3-6, ages 6-11, age $11-15$ years). The version for ages $0-3$ includes 45 items and delivers a comprehensive score describing children's upbringing conditions. Versions for older ages add further aspects of learning and language stimulation as well as modelling and encouraging maturity. In order to make the scaling of the HOME comparable across ages, we standardize the HOME at each age using all observations with a valid HOME score, so that in age the HOME has a mean of zero and a standard deviation of one at each age.

Main explanatory variable. The quality of the ECEC arrangement is assessed with the ORCE, the Observational Ratings of the Caregiving Environment (NICHD 1996). The ORCE focuses on measures of frequency and quality of the interactions between caregivers and children. Several studies show that this quality measure is a meaningful measure (see, e.g., NICHD and Duncan 2003). The ORCE uses a rating scale system of 13 items that assess (each on a four-point scale) the degree of caregivers' sensitivity and reactivity to the children's social signals and (non-)distress, as well as caregiver intrusiveness, their expression of positive feelings toward the infant, their emotional and physical detachment and disengagement, the degree of stimulation targeted at the child's cognitive development, and finally the expression of negative regard for the child as well as flatness of caregiver's affect (NICHD 1996). SECCYD collects information on the ORCE if the care arrangement lasts for 
at least 10 hours per week. ${ }^{11}$ As for the HOME, we take into account the overall total scores including all items and aspects of quality for the ORCE. Again, we standardize the ORCE at each age using all valid SECCYD observations.

Control variables. Our estimation strategy also considers other past and contemporaneous inputs (see Table 1 for an overview of the included variables). In the selection and coding of these control variables, we closely follow NICHD and Duncan (2003). We distinguish between two sets of past inputs, which we subsequently introduce in the estimation of equation (1). While the first set constitutes basic sociodemographic information and measures of the family structure, the second set consists of information regarding the mother's attitudes as well as personality traits of mother and child. The first set of past inputs includes ethnic group (Hispanic, Black, White, other), age at birth (and its square), education (in years), marital status at child birth, employment status of the mother, as well as child gender, number of siblings, an indicator for being firstborn and the birth mode (vaginal delivery, planned Csection, emergency C-section) of the child. Additionally, this first set of past inputs includes some characteristics of the mother's partner (presence of a partner, employment status, years of education) and some household level characteristics (income to poverty ratio, household size, and dummies for each of the 10 sites of data collection ${ }^{12}$ ). The second set of past inputs consists of the mother's general and education-related attitudes (which might affect occupational behavior, parent-child interactions, and the inclination to place the child in a non-family care arrangement) as well as mother's and child's personality characteristics, which might have an influence on parent-child interactions. The variables in this set are included in the SECCYD data and also used by NICHD and Duncan (2003), but these variables are often not observed in other studies. More specifically, this set includes measures of the mother's neuroticism, extraversion, agreeableness, depression, and sensitivity as well as a measure of the child's temperament (all measured when the child was six months old). Furthermore, this set includes measures of the mother's separation anxiety and locus of control as well as her attitudes toward work and toward progressive ideas for raising kids (measured when the child was one month old).

\footnotetext{
${ }^{11}$ SECCYD is mostly interested in non-maternal care. However, in some cases the observed caregiver is the mother of the child. This can be the case if the mother works in a day care center or if she cares for further children besides her own child. Due to endogeneity reasons, we only include children in our main analysis who are cared for by non-family members and, therefore, exclude all children where the observed caregiver is the mother or another family member.

${ }^{12}$ The site fixed effects also account for economic, political, and cultural differences at the regional level.
} 
The set of contemporaneous inputs includes measures of the current values of those historical inputs that vary over time (i.e., income-to-poverty ratio, household size, number of siblings, presence of a partner at home, employment status of the mother and her partner). ${ }^{13}$ In order to avoid losing observations due to missing single items on control variables and in favor of working with a constant sample size, we include a missing dummy indicator for each control variable (and set missing values to the respective variable means).

As SECCYD repeatedly assessed the quality of stimulation in children's home environment as well as the ECEC quality, we not only have the opportunity to control for past HLE quality but we can also examine the relationship between HLE quality and ECEC quality at various points in time. More specifically, we can look at the HLE quality as an outcome variable at three different points in time (when the child is 36 months, 54 months, and about 9 years, respectively). In order to reduce measurement error, in our main specification we average the ECEC quality over the two assessments that precede the respective HLE measure. ${ }^{14}$ Figure 1 provides an overview over this timing and the points in time in which our two quality measures are collected. The figure also shows that in our main specifications, we relate (i) HLE quality at 36 months to ECEC quality averaged over the measures at 15 and 24 months; (ii) HLE quality at 54 months to ECEC quality at 24 and 36 months; and (iii) HLE quality at 9 years to ECEC quality at 36 and 54 months. In the robustness section, we also work with different time spans. ${ }^{15}$ In the main specification, we use the HLE quality collected at age 6 months as baseline measure. Again, we work with different baseline measures in the robustness section. By relying on these time spans and baseline measure, we make sure that our quality measures are collected in a clear temporal sequence: ECEC quality is measured after the baseline HLE measure but before the respective outcome HLE measure.

Descriptive statistics. Table 1 provides summary statistics for the historical and contemporaneous inputs as well as for the measures of ECEC and HLE quality. Summary statistics are displayed for the sample that we use in estimating the effect of ECEC quality on

\footnotetext{
${ }^{13}$ The mother's personality traits and attitudes are only surveyed when the child was one month and six months, respectively. Therefore, we cannot include them as contemporaneous inputs. However, this should not be a major issue as personality traits are often assumed to be stable over time (e.g., Cobb-Clark and Schurer 2012).

${ }^{14}$ If a measure for the ECEC quality is only available for one of the two periods, we use this ECEC measure. In the robustness section, we also work with alternative ways of combining different ECEC measures.

${ }^{15}$ Sample sizes differ between the three versions as the analyses include only children who were cared for by non-family members for at least 10 hours per week (at least at one of the two measurement points of the ECEC quality).
} 
the HLE at age 9 (i.e. in grade 3). ${ }^{16}$ The mean of the HLE is higher when the child is age 9 compared to the baseline measure at month 6 . However, this does not indicate that the HLE improved over time but the higher value is rather due to the different scaling of the HOME scale in the different years; which is why we standardize our quality measures at each measurement point. About $80 \%$ of the mothers in our sample are white and $10 \%$ are black. Mothers were on average 29 years at the birth of the child and $67 \%$ of them are working at baseline, i.e. when the child was six months old. On average, mothers have 14.7 years of education and about $89 \%$ of them live together with a partner at baseline. The table further shows that $46 \%$ of the children are firstborn and on average, they have 0.8 siblings at baseline.

\section{$4 \quad$ Results}

Main results. Table 2 presents the main results of our linear regression models. The first column shows that the quality of the HLE at various ages is positively associated with past ECEC quality. Young children who experience better quality stimulation and care at home also find similar favorable conditions in their ECEC arrangement (see, e.g., NICHD and Duncan 2003). An increase in the ECEC quality by one standard deviation is associated with an increase in HLE by between 0.22 and 0.26 standard deviations, depending on the time window.

When we include controls for basic sociodemographic information and family structure, the coefficients decrease in column (2), as we would expect. However, the coefficients are still positive and statistically significant in two of the three panels. In column (3) we add mother's and child's personality characteristics and attitudes of the mother. This does not alter the coefficients meaningfully compared to the previous specification. Similarly, adding the baseline measure of our outcome HLE in column (4) only marginally changes the estimated coefficients (but the estimates gain slightly in precision). Hence, the value-added specification and the specification controlling for other historical inputs yield the same conclusion. According to column (4) an increase in the ECEC quality by one standard deviation improves the HLE by 0.08 and 0.09 standard deviations in the second and third panel, respectively. While these two coefficients are statistically significant at the 5\%-level, the coefficient in the first panel is not significantly different from zero. The coefficient of 0.03 is smaller than the

\footnotetext{
${ }^{16}$ The summary statistics for the other two samples are very similar.
} 
other two coefficients but not statistically different from them. The overall picture is very similar when we add controls for other contemporaneous inputs in column (5). This is, however, not our preferred specification as these additional controls are measured after the measure of the ECEC quality and might, therefore, be endogenous. ${ }^{17}$

Robustness. The first set of robustness checks deals with the sensitivity of our results to different measures of the baseline HLE and to different periods over which we average ECEC quality. While in our main specification, we measure the baseline HLE when the child was 6 months old, Table 3 shows that our findings are robust to controlling for baseline HLE at age 15 months (column 2) and at ages 6 and 15 months together (column 3). For the third panel, we additionally rely on the HLE measure at age 36 months as baseline measure. Controlling for this baseline measure (column 4) or controlling for all three baseline measures (column 5) does not change the overall pattern of results or our conclusions. In the main specification, we averaged ECEC quality over the two assessments that precede the HLE measure. Our results are robust to averaging ECEC quality over the preceding three (column 6) or four assessments (column 7; computation possible only for Panel C).

While the main specification includes only children who were cared for by non-family members for at least 10 hours per week, in the following we work with alternative sample restrictions (see Table 4). We repeat the analyses and include children that were cared for by non-parental family members (column 2) and children that were cared for by their parents or other family members (column 3). Columns 2 and 3 confirm that the results found in our main analyses are not dependent on our sample restrictions. In fact, taking into account the quality of parental interactions observed via the ORCE also leads to an increase of coefficients and, thus, underlines our first main results. However, these specifications are likely to suffer from endogeneity bias.

In the next set of robustness tests, we study whether the results depend on any minimum amount of care or if they hold only for a limited dosage of care. The SECCYD data includes information on the ECEC quality if the care arrangement lasts for at least 10 hours per week; while we use this definition in our main specification, for robustness purposes we restrict the sample to those children who attend their care arrangements for at least 15, 20, 25, 30, and 35

\footnotetext{
${ }^{17}$ Therefore, the robustness tests in the section are based on the specification applied in column (4) of Table 12. Using column (5) as baseline for the robustness tests produces almost identical results (not shown).
} 
hours per week, respectively. Results for analyses that studied different dosages of care separately are displayed in columns (4)-(8) of Table 4. Again, these analyses confirm the positive effect of ECEC quality on the quality of the HLE.

As a further robustness check, we included ECEC costs as additional control variable; it could be considered as a further contemporaneous input. As higher quality ECEC might be more costly this might affect parental well-being, as there might be a trade-off between better quality and higher ECEC expenses. Nevertheless, once this information is included the results do not differ substantially (column 9). Thus, we find no evidence that our main specification leads to biased results when we do not control for ECEC costs.

Effect heterogeneity. Discussions about targeting ECEC to certain subgroups and results about differential effectiveness of ECEC evoke considerations that the above reported results might not hold for all children but favor certain subpopulations in particular. Moreover, we know that high ECEC quality is particularly important for the development of disadvantaged children, as it could compensate for a lower quality of the HLE. If higher ECEC quality could additionally lead to an increase of the quality of the HLE this would be even more than a pure compensation effect. Thus, we are especially interested how in principle disadvantaged groups are affected.

A final series of analyses therefore studies heterogeneity of effects between certain subgroups. We take into account the child's gender and ethnicity (Caucasian white vs. other) as well as maternal education (two potentially relevant thresholds: $\leq 12$ years and $\leq 14$ years of education) and whether the primary care giver's partner was living in the home or not. Thus, we focus on children of low-educated mothers and single mothers who could be considered as disadvantaged on average. ${ }^{18}$ However, these subgroup analyses partially suffer from rather small sample sizes (compared to the large number of controlling covariates included in the model). Thus, we focus on the overall results and highlight deviating patterns.

The first set of results in Table 5 indicates that both boys' and girls' HLE benefits equally from a high ECEC quality setting. If anything, the results are more pronounced for boys' HLE in the long run. The picture is more diverse for the comparison of Caucasian white children

\footnotetext{
18 Another group that could be considered disadvantaged are children living in income poor households. However, given our relatively small sample size, this group is too small to obtain meaningful results.
} 
vs. other ethnicities. While in the short run (time window 6-36 months), the HLE of nonwhite children benefits most from high ECEC quality, analyses for the time windows 6-54 months and 6 months-age 9 display negative, nonsignificant coefficients. The pattern is reversed for white children's HLE. There is a small negative, non-significant effect of ECEC quality on the HLE for the shortest time window (6-36 months), but strong positive and significant effects for the longer time windows. This indicates that in the long run the HLE of Caucasian white children improves most from high ECEC quality.

Results for subgroup analyses looking at maternal education are similar for the two applied thresholds: The ECEC coefficients for low-educated mothers are not significant and smaller than those for higher educated mothers. All coefficients are positive, with the exception of changes to the HLE of mothers with less than 12 years of education in the shortest time period of 6-36 months. The highest coefficients are observed for the group of children of higher educated mothers in the long run. This translates to advantages of children in households with better educated mothers. Their HLE improves most strongly along with better quality in their ECEC arrangement. Finally, comparisons for single-parent households vs. two-(social)parents households reveals only one deviation from the overall picture found in our main analyses. Coefficients for both subgroups are positive, albeit not always significant and strongest for the group of children of two-parent households in the long run (time window 6 months-age 9). ${ }^{19}$ The only negative but non-significant coefficients in this series of analyses can be found for single-parent households in the longest time frame under study. Generally, we conclude that effects hold for both subgroups with the exception of single-parent households in the long run.

\section{Conclusion}

Although there is a large literature on the effects of high ECEC quality, on the one hand, and high quality of the HLE, on the other, on child development, we know little about the effects of ECEC quality on the HLE. This study attempts to fill this gap by analyzing a sample of the well-known NICHD SECCYD. To our knowledge, this is the most suitable data set for this research questions as it covers several quality measures of ECEC and HLE quality at different points in times. Our empirical framework is built on the models of Todd and Wolpin (2003,

\footnotetext{
${ }^{19}$ The largest coefficient in these analyses appears for single-parent households in the medium length time window (6-54 months). This analysis builds on a very small sample and produces imprecise estimates. Therefore, we refrain from putting too much emphasis on its interpretation.
} 
2007), who distinguish between historical and contemporaneous inputs. We add a baseline measure of the outcome variable and, thus, estimate value-added models. We run various robustness checks related to measurement issues and sample restrictions. Moreover, we consider effect heterogeneity - in particular, we analyze if the HLE of disadvantaged children improves more than that of non-disadvantaged children, especially in the long run.

Overall, we find significant positive effects of ECEC quality on the HLE at later stages. This is particularly true for the ECEC quality that children experience when they are two years and older. For earlier points in time, the relationship is also positive, though not statistically significant.

Our positive effect could be explained by direct and indirect mechanisms: A direct mechanism relates to a more effective interaction between ECEC staff and parents, as one important part of high ECEC quality, which leads to a better quality at home. This interaction might be more effective for relatively older children than for the very young. The closer children get to kindergarten or school entry, the more attention parents might pay to education. Moreover, the longer the child uses ECEC services the more parents may adapt their knowledge and attitudes about childrearing due to interactions with the teachers (e.g., Halgunseth and Peterson 2009). The finding of hardly any negative effect on ECEC quality might indicate that parents do not display compensating behavior at home. Furthermore, there could be indirect effects, in the sense that children talk about their ECEC experience at home and, thus, might evoke or "demand" higher home quality. Our results, particularly those in the analyses considering ECEC measures for relatively older children, support this assumption. Additionally, higher ECEC quality might improve maternal well-being, which in turn raises the HLE.

Heterogeneity analysis indicates that the effects differ between subgroups: Our results show that the HLE of more advantaged children benefits most from high ECEC quality, at least when we consider the long run. With respect to ethnicity, there are different results in the short run, which do not last. The HLE of white children, of children with higher educated mothers, and of children whose mother lives with a partner benefits most if we consider long run effects. Our results indicate that children who might benefit most from high ECEC quality experience smaller effects on their HLE. This might imply an inefficient allocation of ECEC quality. Inequalities in early live circumstances, which exist from the very beginning, might further increase (for such an argumentation, see, e.g., Francesconi and Heckman 2016). 
Consequently, we conclude that if policy makers want to improve the HLE of disadvantaged children in particular, improving the interaction between their parents and the ECEC staff could be one important avenue. Likewise, more effort should be made to improve access to higher quality ECEC for disadvantaged children, e.g. through state regulations, subsidies, and parental education. In principle, this can lead to an increase in the HLE. In any case, such an increase in ECEC quality seems reasonable, as, for example, only $56 \%$ of the sampled children were in center-based care programs that met the child-staff ratio standard of $7: 1$, as defined by the American Public Health Association (McCartney et al. 2007).

However, a design of such measures would benefit from an even better understanding of the mechanisms behind the effects of ECEC quality on the HLE. Given the limited sample size in our data and limited information on potential channels, the mechanisms could not be precisely identified in this study. Future studies employing larger data sets and information on channels of the effects suggested by our study could work on disentangling different mechanisms. Another limitation of our study is that we could not distinguish between different ECEC modes - thus we could not run separate estimations for specific ECEC programs, such as Head Start. Further research is needed to deepen our understanding of the effectiveness of different ECEC services with respect to their effects on HLE of various groups of children.

With these limitations in mind, our results provide promising new evidence suggesting that ECEC quality is an important pathway to improve the HLE of children, not only the other way round. It emphasizes the importance of addressing the quality of various child environments and it emphasizes the necessity of a systematic understanding of the interaction between ECEC and HLE quality.

Acknowledgements: Jan Marcus and Susanne Kuger acknowledge financial support by the College for Interdisciplinary Education Research (CIDER). All authors are CIDER fellows. Mathias Huebener gave very helpful comments to a first draft of the paper. We thank Adam Lederer for helpful editorial assistance and Daniel Skierlo for assistance in setting up a secure data environment for the analysis of the confidential NICHD data. 


\section{References}

Anderson, LM, Shinn C, Fullilove ML, Scrimshaw SC, Fielding JE, Normand J, CarandeKulis VG (2003). The effectiveness of early childhood development programs. A systematic review. American Journal of Preventive Medicine, 24, 32-46.

Araujo MC, Carneiro P, Cruz-Aguayo Y, Schady N. Teacher quality and learning outcomes in kindergarten. The Quarterly Journal of Economics 2016; 7; 1415-1453.

Aughinbaugh A, Gittleman M. Does money matter? A comparison of the effect of income on child development in the United States and Great Britain. Journal of Human Resources $2003 ; 38 ; 416-440$.

Bauchmüller R, Gørtz M, Rasmussen AW. Long-run benefits from universal high-quality preschooling. Early Childhood Research Quarterly 2014; 29; 457-470.

Belsky J, Vandell DL, Burchinal M, Clarke-Stewart KA, McCartney K, Owen MT. Are there long-term effects of early child care? Child development 2007; 78; 681-701.

Benasich AA, Brooks-Gunn J, Clewell BC. How do mothers benefit from early intervention programs? Journal of Applied Developmental Psychology 1992; 13; 311-362.

Berger EM, Spiess CK. Maternal life satisfaction and child outcomes: Are they related?. Journal of Economic Psychology 2011; 32; 142-158.

Bittman M, Craig L, Folbre N 2004. Packaging Care: What happens when children receive nonparental care. In: Folbre N, Bittman M (Eds), Family time: The social organization of care, Routledge: London and New York; 2004.

Blomeyer D, Laucht M, Coneus K, Pfeiffer F. Early life adversity and children's competence development: Evidence from the Mannheim Study of Children at Risk. Jahrbücher für Nationalökonomie und Statistik 2013; 233; 467-485.

Breitmayer BJ, Ramey CT. Biological nonoptimality and quality of postnatal environment as codeterminants of intellectual development. Child Development 1986; 57; 1151-1165.

Booth CL, Clarke-Stewart KA, Vandell DL, McCartney K, Owen MT. Child-care usage and mother-infant 'quality time'. Journal of Marriage and Family 2002; 64; 16-26.

Bowman BT. Preschool as family support. In: Dunst C, Wolery M (Eds), Advances in early education and day care, JAI Press: Greenwich, CT; 1997. p. 157-172.

Brooks-Gunn J, Klebanov PK, Duncan GJ. Ethnic differences in children's intelligence test scores: The role of economic deprivation, home environment, and maternal characteristics. Child Development 1996; 67; 396-408. 
Burger K. How does early childhood care and education affect cognitive development? An international review of the effects of early interventions for children from different social backgrounds. Early Childhood Research Quarterly 2010; 25; 140-165.

Caldwell BM, Bradley RH. Home Observation for Measurement of the Environment: Administration manual. Tempe, AZ: Family and Human Dynamics Research Institute, Arizona State University; 2003.

Camilli G, Vargas S, Ryan S, Barnett WS. Meta-analysis of the effects of early education interventions on cognitive and social development. Teachers College Record 2010; $112 ; 579-620$.

Carneiro P, Rodriguez M. Evaluating the effect of maternal time on child development using the generalized propensity score. Institute for the Study of Labor, 12th IZA European Summer School in Labor Economics; 2009.

Carneiro P, Ginja R. Partial insurance and investments in children. The Economic Journal 2016; 126.

Cobb-Clark DA, Schurer S. The stability of big-five personality traits. Economics Letters 2012; 115; 11-15.

Cunha F, Heckman JJ. The technology of skill formation. American Economic Review Papers and Proceedings; 2007; 97; 31-47

Cunha F, Heckman JJ. The economics and psychology of inequality and human development. Journal of the European Economic Association 2009; 7; 320-364.

Del Boca D, Flinn C, Wiswall M. Household choices and child development. Review of Economic Studies 2014; 81; 137-185.

Del Bono E, Francesconi M, Kelly Y, Sacker A. Early maternal time investment and early child outcomes. The Economic Journal 2016; 126; 96-135.

Elango S, García JL, Heckman JJ, Hojman A. Early childhood education. IZA Discussion Paper 9476. Bonn; 2015.

Francesconi M, Heckman JJ. Child development and parental investment: Introduction. The Economic Journal 2016; 126.

Gilliam WS, Zigler EF. A critical meta-analysis of all evaluations of state-funded preschool from 1977 to 1998: Implications for policy, service delivery and program evaluation. Early Childhood Research Quarterly 2001; 15; 441-473.

Goldberg WA, Greenberger E, Hamill S, O'Neil R. Role demands in the lives of employed single mothers with preschoolers. Journal of Family Issues 1992; 13; 312-333. 
Gordon RA, Usdansky ML, Wang X, Gluzman A. Child care and mothers' mental health: Is high-quality care associated with fewer depressive symptoms? Family Relations 2011; $60 ; 446-460$.

Gorey KM. Early childhood education: A meta-analytic affirmation of the short-and longterm benefits of educational opportunity. School Psychology Quarterly 2001; 16; 9.

Habibov NN. Does childcare have an impact on the quality of parent-child interaction? Evidence from post-Soviet Kyrgyzstan, Tajikistan, and Uzbekistan, Children and Youth Services Review 2012; 34; 2367-2373.

Halgunseth LC, Peterson A. Family engagement, diverse families, and early childhood education programs: An integrated review of the literature. National Association for the Education of Young Children 2009.

Heckman J, Pinto R, Savelyev P. Understanding the mechanisms through which an influential early childhood program boosted adult outcomes. American Economic Review 2013; $103 ; 2052-2086$.

Heckman JJ, Mosso S. The economics of human development and social mobility. Annual Review of Economics 2014; 6; 689-733.

Hsin A, Felfe C. When does time matter? Maternal employment, children's time with parents, and child development. Demography 2014; 51; 1867-1894.

Jensen B, Jensen, P, Würz Rasmussen, A. Does professional development of preschool teachers improve child socio-emotional outcomes? IZA Discussion Paper No. 8957. Bonn; 2015.

Kautz T, Heckman JJ, Diris R, ter Weel B, Borghans L. Fostering and measuring skills: improving cognitive and non-cognitive skills to promote lifetime success. Technical Report, Organisation of Economic Cooperation of Development; 2014.

Kluczniok K, Roßbach HG. Conceptions of educational quality for kindergartens. Zeitschrift für Erziehungswissenschaft 2014; 17; 145-158.

Kremer M. How welfare states care. Culture, gender and parenting in Europe. Amsterdam University Press: Utrecht; 2007.

Lehrl S, Smidt W, Grosse C, Richter D. Patterns of literacy and numeracy activities in preschool and their relation to structural characteristics and children's home activities. Research Papers in Education 2014; 29; 577-597.

McCartney K, Dearing E, Taylor B, Bub KL. Quality child care supports the achievement of low-income children: Direct and indirect pathways through caregiving and the home environment. Journal Applied Developmental Psychology 2007; 28; 411-426. 
Melhuish E, Ereky-Stevens K, Petrogiannis K, Ariescu A, Penderi E, Rentzou K, Tawell A, Slot P, Broekhuizen M, Lesemann P. A review of research on the effects of early childhood education and care (ECEC) on child development. 2015; Retrieved from: http://ecec-

care.org/fileadmin/careproject/Publications/reports/new_version_CARE_WP4_D4_1_ Review_on_the_effects_of_ECEC.pdf

Mocan N. Can consumers detect lemons? An empirical analysis of information asymmetry in the market for child care. Journal of Population Economics; 2007; 20; 743-780.

NICHD Early Child Care Research Network. The NICHD Study of Early Child Care: A comprehensive longitudinal study of young children's lives. ERIC Document Reproduction Service No. ED 353 0870; 1993.

NICHD Early Child Care Research Network. Child care and child development: The NICHD Study of Early Child Care. In: Friedman S L, Haywood H C (Eds), Developmental follow-up: Concepts, domains and methods. Academic Press: New York; 1994. p. 377-396.

NICHD Early Child Care Research Network. Characteristics of infant child care: Factors contributing to positive caregiving. Early Childhood Research Quarterly 1996; 11; 269-306.

NICHD Early Child Care Research Network. Familial factors associated with the characteristics of nonmaternal care for infants. Journal of Marriage and Family 1997; $59 ; 389-408$.

NICHD Early Child Care Research Network. Early child care and children's development prior to school entry: Results from the NICHD Study of Early Child Care. American Educational Research Journal 2002; 39; 133-164.

NICHD Early Child Care Research Network and Greg Duncan. Modeling the impacts of child care quality on children's preschool cognitive development. Child Development 2003; $74 ; 1454-1475$.

Olds DL. Prenatal and infancy home visiting by nurses: From randomized trials to community replication. Prevention Science 2002: 3; 153-172.

Olds DL, Kitzman H, Hanks C, Cole R, Anson E, Sidora-Arcoleo K, Luckey D W, Henderson CR, Holmberg J, Tutt RA, Stevenson AJ, Bondy J. Effects of nurse home visiting on maternal and child functioning: age-9 follow-up of a randomized trial. Pediatrics 2007; $120 ; 832-845$.

Payne SC, Cook AL, Diaz I. Understanding childcare satisfaction and its effect on workplace 
outcomes: The convenience factor and the mediating role of work-family conflict. Journal of Occupational and Organizational Psychology 2011; 85; 225-244.

Poms LW, Botsford WE, Kaplan SA, Buffardi LC, O'Brien AS. The economic impact of work and family issues: Child care satisfaction and financial considerations of employed mothers. Journal of Occupational Health Psychology 2009; 14; 402.

Sammons P, Anders Y, Sylva K, Melhuish E, Siraj-Blatchford I, Taggart B, Barreau S. Children's cognitive attainment and progress in English primary schools during Key Stage 2. Investigating the potential continuing influencesof pre-school education. Zeitschrift für Erziehungswissenschaft Special Edition 2008; 10; 179-198.

Scarr S, McCartney K. How people make their own environments: A theory of genotypeenvironment effects. Child development 1983; 424-435.

Schweinhart LJ, Barnes HV, Weikart DP. Significant benefits: The High-Scope Perry Preschool Study through age 27. Ypsilanti, MI: High/Scope Press; 1993.

Todd $\mathrm{P}$, Wolpin $\mathrm{K}$. On the specification and estimation of the production function for cognitive achievement. The Economic Journal 2003; 113; 3-33.

Todd P, Wolpin, K. The production of cognitive achievement in children: Home, school, and racial test score gaps. Journal of Human Capital 2007; 1; 91-136.

Vandell DL, Belsky J, Burchinal M, Steinberg L, Vandergrift N. Do effects of early child care extend to age 15 years? Results from the NICHD Study of Early Child Care and Youth Development. Child Development 2010; 81; 737-756. 
Table 1: Summary statistics

\begin{tabular}{|c|c|c|c|}
\hline Variable & Mean & Std. Dev. & $\mathbf{N}$ \\
\hline \multicolumn{4}{|l|}{ Measures of the dependent variable } \\
\hline HOME total score at 6 months (raw) & 36.999 & 4.34 & 721 \\
\hline HOME total score at 36 months (raw) & 42.311 & 7.132 & 710 \\
\hline HOME total score at 54 months (raw) & 46.564 & 5.146 & 688 \\
\hline HOME total score in grade 3 (raw) & 46.970 & 6.220 & 721 \\
\hline \multicolumn{4}{|l|}{ Measures of the main explanatory } \\
\hline ECEC quality (ORCE 36 months, raw) & 2.791 & 0.459 & 422 \\
\hline ECEC quality (ORCE 54 months, raw) & 3.013 & 0.562 & 656 \\
\hline ECEC quality (ORCE $36 \& 54$ months, raw) & 2.952 & 0.481 & 721 \\
\hline \multicolumn{4}{|c|}{$\begin{array}{l}\text { Historical inputs I (measured at or before age } 6 \text { months) } \\
\text { Maternal characteristics }\end{array}$} \\
\hline White & 0.803 & 0.398 & 721 \\
\hline Black & 0.105 & 0.307 & 721 \\
\hline Hispanic & 0.049 & 0.215 & 721 \\
\hline Other non-white & 0.043 & 0.203 & 721 \\
\hline Mother's age & 29.082 & 5.435 & 721 \\
\hline Mother's age sq. & 875.248 & 315.506 & 721 \\
\hline Mother's education (in years) & 14.73 & 2.406 & 721 \\
\hline Married at birth & 0.814 & 0.389 & 721 \\
\hline Mother is employed and currently working & 0.669 & 0.471 & 721 \\
\hline \multicolumn{4}{|l|}{ Child characteristics } \\
\hline Female child & 0.510 & 0.500 & 721 \\
\hline No. of siblings & 0.813 & 0.905 & 721 \\
\hline Firstborn & 0.459 & 0.499 & 721 \\
\hline Vaginal delivery & 0.784 & 0.412 & 721 \\
\hline Planned C-section & 0.078 & 0.268 & 721 \\
\hline Emergency C-section & 0.139 & 0.346 & 721 \\
\hline \multicolumn{4}{|l|}{ Paternal characteristics } \\
\hline Partner lives at home & 0.889 & 0.314 & 721 \\
\hline Partner's education & 14.982 & 2.527 & 721 \\
\hline Missing & 0.065 & 0.247 & 721 \\
\hline Partner is employed and currently working & 0.828 & 0.378 & 721 \\
\hline \multicolumn{4}{|l|}{ Household characteristics } \\
\hline Income to poverty threshold ratio & 4.103 & 3.262 & 721 \\
\hline Missing & 0.008 & 0.091 & 721 \\
\hline$\overline{\mathrm{HH}}$ size & 3.932 & 1.079 & 721 \\
\hline Site: University of Arkansas & 0.094 & 0.292 & 721 \\
\hline Site: University of California at Irvine & 0.122 & 0.328 & 721 \\
\hline Site: University of Kansas & 0.11 & 0.313 & 721 \\
\hline Site: University of Wellesley & 0.086 & 0.281 & 721 \\
\hline Site: University of Pittsburgh & 0.105 & 0.307 & 721 \\
\hline Site: Temple University & 0.093 & 0.291 & 721 \\
\hline
\end{tabular}


... table 1 continued

\begin{tabular}{lccc}
\hline \multicolumn{1}{c}{ Variable } & Mean & Std. Dev. & N \\
\hline Site: University of Virginia & 0.090 & 0.287 & 721 \\
Site: University of Washington & 0.108 & 0.311 & 721 \\
Site: Western Carolina Center & 0.094 & 0.292 & 721 \\
Site: University of Wisconsin & 0.097 & 0.296 & 721
\end{tabular}

Historical inputs II (measured at or before age 6 months)

Maternal neuroticism Missing

Maternal extraversion Missing

Maternal agreeableness Missing

Maternal depression Missing

Maternal sensitivity Missing

Maternal assessment of child temperament

Mother's separation anxiety Missing

Parental Locus of Control Missing

Attitude: Benefits of maternal employment

Progressive ideas for raising kids Missing

29.597

0.010

42.683

7.035

0.098

5.642

$0.010 \quad 0.098$

46.493

5.129

0.010

8.968

0.001

9.339

0.004

3.149

68.435

0.014

48.227

0.015

19.317

33.125

0.003

0.098

8.359

0.037

1.729

0.064

0.403

12.951

0.117

7.217

0.123

3.047

3.391

0.053

721

721

721

721

721

721

721

721

721

721

721

721

721

721

721

721

721

721

Contemporaneous inputs for Panel $\mathbf{C}$ (measured in grade 3)

\begin{tabular}{llll} 
Income to poverty threshold ratio & 4.723 & 3.609 & 721 \\
$\quad$ Missing & 0.058 & 0.234 & 721 \\
HH size & 4.238 & 1.040 & 721 \\
$\quad$ Missing & 0.015 & 0.123 & 721 \\
No. of siblings & 2.335 & 0.920 & 721 \\
$\quad$ Missing & 0.015 & 0.123 & 721 \\
Partner lives at home & 0.817 & 0.384 & 721 \\
$\quad$ Missing & 0.015 & 0.123 & 721 \\
Mother is employed and currently working & 0.768 & 0.422 & 721 \\
Partner is employed and currently working & 0.763 & 0.426 & 721 \\
\hline
\end{tabular}

Note: The table provides summary statistics for selected variables. "Missing" indicates the share of observations with missing values for the specific variable. Missing values are set to the respective variable means. If all respondents provided valid information for a given variable, no "missing"-indicator is listed. Source: Own calculations based on NICHD SECCYD data. 
Figure 1: Overview over the study design

\section{Early childhood education and care Kindergarten and school}

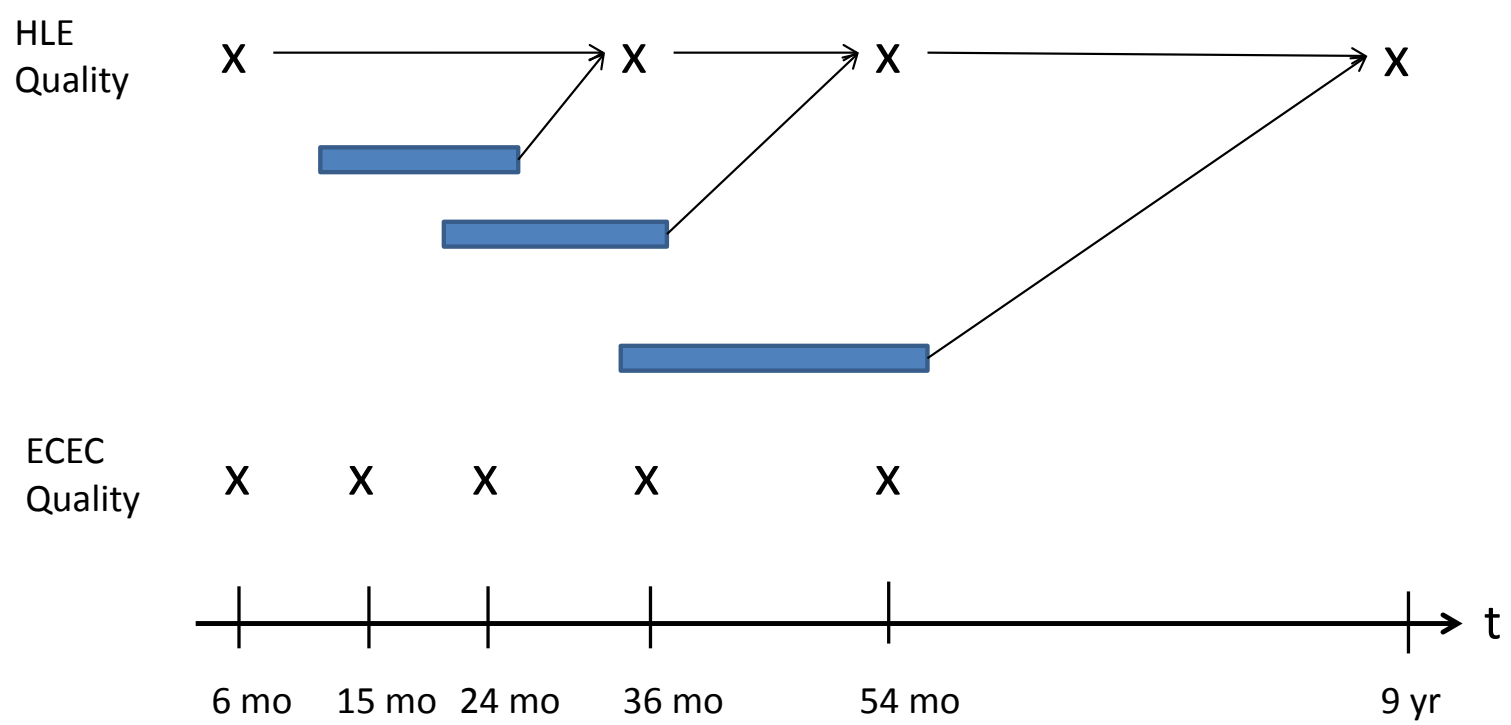

Note: The figure provides an overview over the study design. In particular, it shows the timing of the measurement of the quality of the early education and care quality as well as the quality of the home learning environment. 
Table 2: Main table: Effect of ECEC quality on home learning environment

\begin{tabular}{|c|c|c|c|c|c|}
\hline & $\begin{array}{c}\text { Raw } \\
\text { correlation } \\
(1)\end{array}$ & $\begin{array}{c}(1)+ \\
\text { Historical } \\
\text { inputs } 1 \\
(2)\end{array}$ & $\begin{array}{c}(2)+ \\
\text { Historical } \\
\text { inputs } 2 \\
(3)\end{array}$ & $\begin{array}{c}(3)+ \\
\text { Value added } \\
\text { model } \\
(4)\end{array}$ & $\begin{array}{c}(4)+ \\
\text { Contemp. } \\
\text { inputs } \\
(5)\end{array}$ \\
\hline \multicolumn{6}{|c|}{ Panel A: HLE at age 36 months } \\
\hline ECEC Quality & $\begin{array}{c}0.231^{* * *} \\
(0.044)\end{array}$ & $\begin{array}{c}0.027 \\
(0.037)\end{array}$ & $\begin{array}{c}0.043 \\
(0.037)\end{array}$ & $\begin{array}{c}0.040 \\
(0.035)\end{array}$ & $\begin{array}{c}0.031 \\
(0.035)\end{array}$ \\
\hline $\mathrm{N}$ & 486 & 486 & 486 & 486 & 486 \\
\hline $\mathrm{R}^{2}$ & 0.06 & 0.45 & 0.48 & 0.50 & 0.52 \\
\hline \multicolumn{6}{|c|}{ Panel B: HLE at age 54 months } \\
\hline ECEC Quality & $\begin{array}{c}0.262^{* * *} \\
(0.045)\end{array}$ & $\begin{array}{l}0.082^{*} \\
(0.042)\end{array}$ & $\begin{array}{l}0.078^{*} \\
(0.040)\end{array}$ & $\begin{array}{c}0.078 * * \\
(0.039)\end{array}$ & $\begin{array}{c}0.080 * * \\
(0.038)\end{array}$ \\
\hline $\mathrm{N}$ & 494 & 494 & 494 & 494 & 494 \\
\hline $\mathrm{R}^{2}$ & 0.07 & 0.48 & 0.52 & 0.54 & 0.56 \\
\hline \multicolumn{6}{|c|}{ Panel C: HLE in grade 3} \\
\hline ECEC Quality & $\begin{array}{c}0.218^{* * *} \\
(0.042)\end{array}$ & $\begin{array}{c}0.092^{* *} \\
(0.036)\end{array}$ & $\begin{array}{c}0.094^{* * *} \\
(0.035)\end{array}$ & $\begin{array}{c}0.088 * * \\
(0.035)\end{array}$ & $\begin{array}{c}0.072^{* *} \\
(0.035)\end{array}$ \\
\hline $\mathrm{N}$ & 721 & 721 & 721 & 721 & 721 \\
\hline $\mathrm{R}^{2}$ & 0.04 & 0.41 & 0.44 & 0.45 & 0.51 \\
\hline Historical 1: & no & yes & yes & yes & yes \\
\hline Historical 2: & no & no & yes & yes & yes \\
\hline Baseline HOME: & no & no & no & yes & yes \\
\hline Contemporaneous: & no & no & no & no & yes \\
\hline
\end{tabular}

Note: The table displays the effect of ECEC quality (measured by the standardized ORCE) on the home learning environment (HLE; standardized) at various points in time, as indicated in the panel header. Further sets of control variables are included as stated in the table's lower part. ECEC quality is averaged over the measures at 15 and 24 months for Panel A, the measures at ages 24 and 36 months for Panel B, and the measures at ages 36 and 54 months for Panel C. Robust standard errors in parentheses: ${ }^{*} p<0.1$; ** $p<0.05 ; * * * p<0.01$.

Source: Own calculations based on NICHD SECCYD data. 
Table 3: Robustness I: Different model specifications

\begin{tabular}{|c|c|c|c|c|c|c|c|}
\hline & \multirow{2}{*}{$\begin{array}{l}\text { Main } \\
\text { model } \\
(1)\end{array}$} & \multicolumn{4}{|c|}{ Baseline HOME at month } & \multicolumn{2}{|c|}{ ORCE averaged over } \\
\hline & & $\begin{array}{l}15 \\
(2)\end{array}$ & $\begin{array}{c}6,15 \\
(3)\end{array}$ & $\begin{array}{l}36 \\
(4)\end{array}$ & $\begin{array}{c}6,15,36 \\
(5)\end{array}$ & $\begin{array}{c}3 \text { periods } \\
(6)\end{array}$ & $\begin{array}{c}4 \text { periods } \\
(7)\end{array}$ \\
\hline \multicolumn{8}{|c|}{ Panel A: HLE at age 36 months } \\
\hline \multirow[t]{2}{*}{ ECEC Quality } & 0.040 & 0.000 & 0.001 & & & 0.049 & \\
\hline & $(0.035)$ & $(0.033)$ & $(0.032)$ & & & $(0.037)$ & \\
\hline $\mathrm{N}$ & 486 & 480 & 480 & & & 522 & \\
\hline $\mathrm{R}^{2}$ & 0.50 & 0.55 & 0.56 & & & 0.51 & \\
\hline \multicolumn{8}{|c|}{ Panel B: HLE at age 54 months } \\
\hline \multirow[t]{2}{*}{ ECEC Quality } & $0.078^{* *}$ & $0.065^{*}$ & $0.066^{*}$ & & & $0.132^{* * *}$ & \\
\hline & $(0.039)$ & $(0.036)$ & $(0.036)$ & & & $(0.038)$ & \\
\hline $\mathrm{N}$ & 494 & 490 & 490 & & & 531 & \\
\hline $\mathrm{R}^{2}$ & 0.54 & 0.57 & 0.57 & & & 0.54 & \\
\hline \multicolumn{8}{|c|}{ Panel C: HLE in grade 3} \\
\hline \multirow[t]{2}{*}{ ECEC Quality } & $0.088^{* *}$ & $0.075^{* *}$ & $0.073^{* *}$ & $0.084^{* *}$ & $0.071^{* *}$ & $0.084^{* *}$ & $0.089 * *$ \\
\hline & $(0.035)$ & $(0.035)$ & $(0.035)$ & $(0.034)$ & $(0.034)$ & $(0.036)$ & $(0.036)$ \\
\hline $\mathrm{N}$ & 721 & 712 & 712 & 710 & 701 & 741 & 762 \\
\hline $\mathrm{R}^{2}$ & 0.45 & 0.47 & 0.48 & 0.48 & 0.49 & 0.46 & 0.46 \\
\hline
\end{tabular}

Note: The table displays various robustness tests for the effect of ECEC quality on the home learning environment (HLE) at various points in time, as indicated in the panel header. All specifications control for historical inputs and a baseline measure of the home learning environment (at age 6 months for columns 1, 6 and 7). For columns (1)-(5), ECEC quality is averaged over the measures at 15 and 24 months for Panel A, the measures at ages 24 and 36 months for Panel B, and the measures at ages 36 and 54 months for Panel C. For columns (6) and (7), ECEC quality is averaged over the previous three and four periods, respectively. Robust standard errors in parentheses: ${ }^{*} p<0.1{ }^{* *} p<0.05 ; * * *$ $p<0.01$.

Source: Own calculations based on NICHD SECCYD data. 
Table 4: Robustness tests II: Different sample restrictions

\begin{tabular}{|c|c|c|c|c|c|c|c|c|c|}
\hline & \multirow[b]{2}{*}{$\begin{array}{l}\text { Main } \\
(1)\end{array}$} & \multicolumn{2}{|c|}{ Care } & \multicolumn{5}{|c|}{ at least X hours/week of care } & \multirow[b]{2}{*}{$\begin{array}{c}+ \text { Cost } \\
(9)\end{array}$} \\
\hline & & $\begin{array}{c}\text { Non-parent. } \\
(2)\end{array}$ & $\begin{array}{l}\text { All } \\
(3)\end{array}$ & $\begin{array}{l}\geq 15 \\
(4)\end{array}$ & $\begin{array}{l}\geq 20 \\
(5)\end{array}$ & $\underset{(6)}{\geq 25}$ & $\begin{array}{l}\geq 30 \\
(7)\end{array}$ & $\begin{array}{c}\geq 35 \\
(8)\end{array}$ & \\
\hline \multicolumn{10}{|c|}{ Panel A: HLE at age 36 months } \\
\hline ECEC Quality & $\begin{array}{c}0.040 \\
(0.035)\end{array}$ & $\begin{array}{l}0.051^{*} \\
(0.031)\end{array}$ & $\begin{array}{c}0.070^{* *} \\
(0.028)\end{array}$ & $\begin{array}{c}0.056 \\
(0.036)\end{array}$ & $\begin{array}{l}0.061^{*} \\
(0.037)\end{array}$ & $\begin{array}{c}0.060 \\
(0.039)\end{array}$ & $\begin{array}{l}0.070^{*} \\
(0.040)\end{array}$ & $\begin{array}{c}0.056 \\
(0.042)\end{array}$ & $\begin{array}{c}0.040 \\
(0.036)\end{array}$ \\
\hline $\mathrm{N}$ & 486 & 615 & 762 & 471 & 448 & 427 & 403 & 369 & 486 \\
\hline $\mathrm{R} 2$ & 0.50 & 0.51 & 0.51 & 0.51 & 0.51 & 0.51 & 0.52 & 0.52 & 0.50 \\
\hline \multicolumn{10}{|c|}{ Panel B: HLE at age 54 months } \\
\hline ECEC Quality & $\begin{array}{c}0.078^{* *} \\
(0.039)\end{array}$ & $\begin{array}{c}0.088^{* *} \\
(0.037)\end{array}$ & $\begin{array}{c}0.112^{* * *} \\
(0.034)\end{array}$ & $\begin{array}{c}0.093^{* *} \\
(0.040)\end{array}$ & $\begin{array}{c}0.084^{* *} \\
(0.042)\end{array}$ & $\begin{array}{l}0.085^{*} \\
(0.044)\end{array}$ & $\begin{array}{l}0.093^{*} \\
(0.047)\end{array}$ & $\begin{array}{l}0.099^{*} \\
(0.051)\end{array}$ & $\begin{array}{l}0.072^{*} \\
(0.040)\end{array}$ \\
\hline $\mathrm{N}$ & 494 & 588 & 697 & 478 & 461 & 438 & 401 & 365 & 494 \\
\hline $\mathrm{R} 2$ & 0.54 & 0.51 & 0.50 & 0.54 & 0.54 & 0.54 & 0.55 & 0.53 & 0.54 \\
\hline \multicolumn{10}{|c|}{ Panel C: HLE in grade 3} \\
\hline ECEC Quality & $\begin{array}{c}0.088^{* *} \\
(0.035)\end{array}$ & $\begin{array}{c}0.100^{* * *} \\
(0.035)\end{array}$ & $\begin{array}{c}0.117^{* * *} \\
(0.034)\end{array}$ & $\begin{array}{c}0.094^{* *} \\
(0.039)\end{array}$ & $\begin{array}{c}0.084^{* *} \\
(0.039)\end{array}$ & $\begin{array}{l}0.074^{*} \\
(0.041)\end{array}$ & $\begin{array}{c}0.086^{* *} \\
(0.042)\end{array}$ & $\begin{array}{l}0.080^{*} \\
(0.044)\end{array}$ & $\begin{array}{c}0.088^{* *} \\
(0.035)\end{array}$ \\
\hline $\mathrm{N}$ & 721 & 774 & 828 & 644 & 604 & 563 & 520 & 477 & 721 \\
\hline $\mathrm{R} 2$ & 0.45 & 0.46 & 0.46 & 0.45 & 0.45 & 0.44 & 0.44 & 0.44 & 0.46 \\
\hline
\end{tabular}

Note: (1) repeats the main results. (2) includes ORCES measures of all care-givers except parents. (3) includes ORCE measures of any care-giver (including family members). Columns (4)-(8) include only children who have at least a specific number of hours of care per week by non-family members in one of the ORCE periods, where the specific number is indicated by the column header. Robust standard errors in parentheses: ${ }^{*} p<0.1 ;{ }^{* *} p<0.05 ;{ }^{* * *} p<0.01$.

Source: Own calculations based on NICHD SECCYD data. 
Table 5: Effect heterogeneity

\begin{tabular}{|c|c|c|c|c|c|c|c|c|c|c|}
\hline & \multicolumn{4}{|c|}{ Child is } & \multicolumn{4}{|c|}{ Maternal education } & & \\
\hline & \multicolumn{2}{|c|}{ female } & \multicolumn{2}{|c|}{ white } & \multicolumn{2}{|c|}{$>14$ years } & \multicolumn{2}{|c|}{$>12$ years } & \multicolumn{2}{|c|}{ Partner at home } \\
\hline & no & yes & no & yes & no & yes & no & yes & no & yes \\
\hline \multicolumn{11}{|c|}{ Panel A: HLE at age 36 months } \\
\hline \multirow[t]{2}{*}{ ECEC Quality } & 0.02 & 0.02 & $0.22^{*}$ & -0.01 & 0.05 & 0.02 & -0.07 & 0.05 & 0.09 & 0.01 \\
\hline & $(0.05)$ & $(0.06)$ & $(0.13)$ & $(0.04)$ & $(0.05)$ & $(0.05)$ & $(0.11)$ & $(0.04)$ & $(0.30)$ & $(0.04)$ \\
\hline $\mathrm{N}$ & 250 & 236 & 76 & 410 & 248 & 238 & 90 & 396 & 53 & 433 \\
\hline $\mathrm{R} 2$ & 0.56 & 0.54 & 0.79 & 0.48 & 0.52 & 0.34 & 0.73 & 0.45 & 0.90 & 0.50 \\
\hline \multicolumn{11}{|c|}{ Panel B: HLE at age 54 months } \\
\hline \multirow[t]{2}{*}{ ECEC Quality } & 0.04 & 0.08 & -0.05 & $0.09^{* *}$ & 0.07 & $0.10^{* *}$ & 0.10 & $0.08^{* *}$ & 0.19 & 0.06 \\
\hline & $(0.06)$ & $(0.05)$ & $(0.13)$ & $(0.04)$ & $(0.07)$ & $(0.05)$ & $(0.15)$ & $(0.04)$ & $(0.46)$ & $(0.04)$ \\
\hline $\mathrm{N}$ & 246 & 248 & 87 & 407 & 260 & 234 & 108 & 386 & 51 & 443 \\
\hline $\mathrm{R} 2$ & 0.61 & 0.56 & 0.72 & 0.50 & 0.50 & 0.40 & 0.61 & 0.50 & 0.84 & 0.52 \\
\hline \multicolumn{11}{|c|}{ Panel C: HLE in grade 3} \\
\hline \multirow[t]{2}{*}{ ECEC Quality } & $0.11^{* *}$ & 0.08 & -0.10 & $0.13^{* * *}$ & 0.05 & $0.16^{* * *}$ & 0.09 & $0.09^{* *}$ & -0.08 & $0.10^{* * *}$ \\
\hline & $(0.06)$ & $(0.05)$ & $(0.10)$ & $(0.04)$ & $(0.05)$ & $(0.05)$ & $(0.09)$ & $(0.04)$ & $(0.15)$ & $(0.04)$ \\
\hline $\mathrm{N}$ & 353 & 368 & 142 & 579 & 413 & 308 & 169 & 552 & 80 & 641 \\
\hline $\mathrm{R} 2$ & 0.54 & 0.44 & 0.58 & 0.41 & 0.42 & 0.34 & 0.42 & 0.41 & 0.61 & 0.44 \\
\hline
\end{tabular}

Note: The table the effect of ECEC quality on the home learning environment (HLE) for various subgroups. The sample is split according to the grouping variable as indicated by the column header. Robust standard errors in parentheses: ${ }^{*} p<0.1 ; * * p<0.05 ; * * * p<0.01$.

Source: Own calculations based on NICHD SECCYD data. 